\title{
LH and testosterone responses to GnRH in red deer (Cervus elaphus) stags kept in a manipulated photoperiod
}

\author{
J. M. Suttie, P. F. Fennessy, I. D. Corson, F. J. Laas, H. J. Elgar* and \\ K. R. Lapwood* \\ Invermay Agricultural Centre, Private Bag, Mosgiel, New Zealand; and ${ }^{*}$ Department of Physiology \\ and Anatomy, Massey University, Palmerston North, New Zealand
}

\begin{abstract}
Summary. Six red deer stags from age 4 months were kept in a light-proof room under an artificial photoperiod consisting of 5.5 cycles of alternate 2 -month periods of $16 \mathrm{~h}$ light and $8 \mathrm{~h}$ dark (16L:8D) and 8L:16D. At 2 or 3 weekly intervals from 10 months of age through 4 cycles, the stags were anaesthetized with xylazine and challenged i.v. with $10 \mu \mathrm{g}$ GnRH. Blood samples were withdrawn immediately before and 10 and $60 \mathrm{~min}$ after injection. $\mathrm{LH}$ and testosterone concentrations were measured in all samples by RIA. Antler status was recorded daily. Peak LH values on each sampling day occurred in the sample taken $10 \mathrm{~min}$ after $\mathrm{GnRH}$ stimulation while peak testosterone occurred in the sample taken at $60 \mathrm{~min}$. There were 4 cycles of $\mathrm{LH}$ and testosterone secretion accompanied by 4 antler cycles in the stags. The highest $\mathrm{LH}$ responses were detected during short days $(8 \mathrm{~L}: 16 \mathrm{D})$, and the highest testosterone responses were detected around the time of the change from short to long days. The responses of both hormones were lowest at the end of periods of long days or the beginning of short days. The increased pituitary LH response to GnRH was evident 4 weeks after the change to short days which are stimulatory for gonadal development. Antler casting occurred at the end of long days and cleaning at the end of short days. It is considered that antler cycles were due to the ability of the stags to vary release of $\mathrm{LH}$ and testosterone in response to changes in the artificial photoperiod.
\end{abstract}

Keywords: luteinizing hormone; testosterone; red deer; photoperiod

\section{Introduction}

Red deer (Cervus elaphus) are normally regarded as short-day breeders because the peak of mating activity occurs in the autumn (Lincoln, 1971). Annual cycles of antler growth and replacement are closely allied with the annual cycles of reproduction and both are synchronized with cyclic changes in photoperiod (Lincoln, 1971; Lincoln \& Kay, 1979; Suttie et al., 1984b; Fennessy \& Suttie, 1985). Plasma concentrations of testosterone are very low when the hard antlers are cast in the spring and they remain low during the subsequent velvet antler growth which begins immediately after casting. The concentrations rise to high levels when the antlers become clean of velvet in late summer. Peak plasma testosterone values are reached during the autumn rut (intense breeding activity) and thereafter they fall during the winter until antler casting in spring.

Although it has been known for some time that the antler cycle can be manipulated by artificial changes in daylength (Goss, 1969; Simpson et al., 1983/4), the endocrine changes associated with this photoperiodic manipulation have been little studied. Therefore, the aim of the present study was to investigate changes in luteinizing hormone (LH) and testosterone in red deer stags which were subject to 4 light:dark cycles over a 16-month period and which consequently grew 4 sets of 
antlers during that time, to determine whether changes in the secretory pattern of these hormones could be associated with the timing of the antler cycle. The $\mathrm{LH}$ and the testosterone responses to gonadotrophin-releasing hormone $(\mathrm{GnRH})$ were used as an indicator of endocrine status of the stags. Voluntary food intake, testicular development and antler data have already been published from the present study (Suttie et al., 1984a).

\section{Materials and Methods}

Animals and treatments. Six prepubertal red deer stags aged 4 months at the start of the trial were kept individually in pens in a light-proof room. They were exposed to an artificial photoperiod of 2 months of $16 \mathrm{~h} \mathrm{light}$ and $8 \mathrm{~h}$ dark (16L:8D) per day followed by 2 months of $8 \mathrm{~L}: 16 \mathrm{D}$ per day, alternating for $5 \cdot 5$ cycles. Lighting was provided by fluorescent bulbs, with an intensity of 500 lux at 1 metre from the floor of the pens. From 10 months of age (the start of a short-day phase) at 2 or 3 weekly intervals (1, 4 and 7 weeks after each light change) the stags were anaesthetized with $100 \mathrm{mg}$ xylazine (Rompun: Bayer (NZ) Ltd, Petone, New Zealand) given intramuscularly and then challenged with a single intravenous injection of $10 \mu \mathrm{g}$ GnRH (Sigma Chemicals, St Louis, MO, USA). Blood samples were withdrawn immediately before and 10 and $60 \mathrm{~min}$ after the injection. The abbreviated sampling regimen was chosen to maximize the scope of the study while keeping the number of samples to a minimum, and because frequently repeated immobilization of deer with xylazine affects appetite and hence growth (Simpson et al., 1983). This effect is minimized by keeping the deer under anaesthesia for as short a time as possible. Previous research with deer involving more frequent blood sampling regimens has indicated that peak LH occurs $10-15 \mathrm{~min}$ after a challenge with GnRH and peak testosterone 60-75 min after (Suttie et al., 1984b). Antler status (i.e. whether in velvet or hard antler) was recorded daily while antler length (from the top of the head to the antler tip) was measured while under anaesthesia (cycle 1, 10-14 months of age; cycle 2,14-18 months of age and so on). As indicated by the antler cycles, the stags became sexually mature during the period of the study.

Hormone analysis. All plasma samples were analysed for LH and testosterone. LH concentration was measured using the method of Niswender et al. (1969) as modified by Barrell \& Lapwood (1978/9). The assay was validated for cervine plasma (Fennessy et al., 1988). The antiserum used was anti-ovine LH (GDN No. 15 from Dr G. D. Niswender, Colorado State University, CO, USA), the labelled ligand was LER 1347A and the standard was NIHLH-S18 (NIH, Bethesda, MD, USA). The inter- and intra-assay coefficients of variation were determined from 3 pools of plasma assayed between and within all assays. Inter-assay values were $11 \cdot 4,9.6$ and $14.8 \%$ for pools of (mean \pm s.d.) $4.21 \pm 0.48,2.49 \pm 0.24$ and $0.44 \pm 0.07 \mathrm{ng} / \mathrm{ml}$ respectively. The intra-assay coefficients of variation were $6 \cdot 1,4 \cdot 6$ and $8 \cdot 2 \%$. The assay sensitivity was $0.08 \mathrm{ng} / \mathrm{ml}$.

Testosterone concentration was measured using the method of Smith \& Hafs (1973) as modified by Wilson \& Lapwood (1979) and validated for use with cervine plasma by Fennessy et al. (1988). The antiserum was raised against testosterone-3-(0-carboxymethyl)-oxime-BSA by Dr G. D. Niswender (batch No. S250). The labelled ligand was $\left[2,4,6,7-{ }^{3} \mathrm{H}\right]$ testosterone (sp. act. 84-109 $\mathrm{Ci} / \mathrm{mmol}$ : Radiochemical Centre, Amersham, UK) and the standard was testosterone (T-1500: Sigma). The inter-assay coefficients of variation were $8.8,11 \cdot 6$ and $23.3 \%$ for pools containing $5.51 \pm 0.48,2.59 \pm 0.30$ and $0.72 \pm 0.17 \mathrm{ng} / \mathrm{ml}$ respectively. Intra-assay sensitivity coefficients of variation were 6.2 , $9 \cdot 6$ and $24.3 \%$ respectively. The sensitivity of the assay was $0.1 \mathrm{ng} / \mathrm{ml}$.

Biometric analysis. The peak of LH always occurred in the sample taken at $10 \mathrm{~min}$ and the highest value of testosterone in the sample taken $60 \mathrm{~min}$ after the i.v. challenge of GnRH. The LH response values presented in Figs 1 and 2 are the incremental changes in concentration between the 0 time and 10 -min sample while the testosterone values are the incremental change between the mean of the 0 and 10 -min sample values and the sample concentration at $60 \mathrm{~min}$.

\section{Results}

The mean LH and testosterone concentrations for the samples taken immediately before the GnRH challenge (i.e. the basal levels) are presented in Fig. 1(a). The cyclic pattern of the change in concentrations which is particularly clear for testosterone, is evidence of a cyclic change in endogenous activity in response to the 4 periods of alternating short and long days. The basal LH concentration increased towards the end of the long-day phase and reached a peak during the early-mid short days. The basal testosterone lagged behind the $\mathrm{LH}$, increasing through the short-day phase to reach a maximum during the late short days or early long-day phase.

Mean LH and testosterone responses after GnRH challenges throughout the study are presented in Fig. 1(b). All stags responded to the challenge on each occasion and, as with the basal values, there were 4 cycles of $\mathrm{LH}$ and testosterone secretion in response to the 4 periods of 


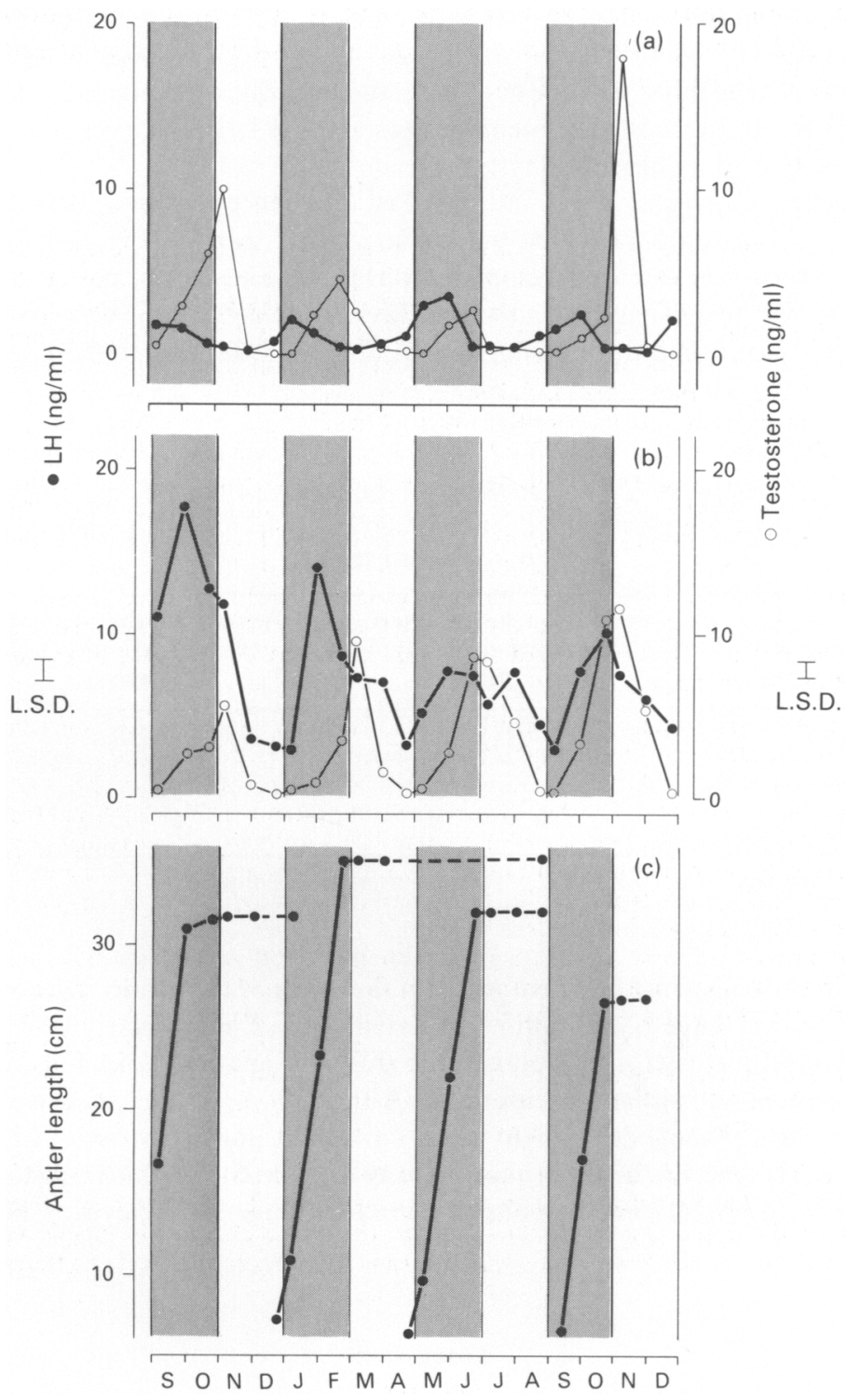

Fig. 1. Testosterone, LH and antler responses of red deer stags. (a) Mean plasma LH and testosterone concentrations for the 6 stags for the sample taken at 0 min immediately before the GnRH challenge on each occasion. (b) Mean LH and testosterone responses to $10 \mu \mathrm{g} G \mathrm{GH}$ given intravenously. The LH response is calculated as the difference between the plasma $\mathrm{LH}$ concentration at $10 \mathrm{~min}$ after the GnRH challenge and that taken immediately before the challenge $(0 \mathrm{~min})$. The testosterone response is calculated as the difference between the plasma testosterone concentration at $60 \mathrm{~min}$ after the GnRH challenge and the mean of the samples at 0 and $10 \mathrm{~min}$. (c) Mean antler length in the 6 stags. The stippled area indicates the 2-month periods of short days (8L:16D) and the unstippled area the 2-month periods of long days (16L:8D). LSD is the least significant difference. The broken line indicates that antler casting had begun in the group but had not finished. Thus one stag failed to cast his second antler until the remainder of the group had cast their third antlers. 
alternating short and long days. LH responses to $\mathrm{GnRH}$ were maximal during short days, and had begun to fall before or just after the abrupt change to long days. In addition maximal $\mathrm{LH}$ responses tended to decrease in magnitude as the study progresed. Testosterone responses to the GnRHinduced LH secretion started to increase during short days and the peak usually occurred at the start of the periods of long days or at the end of short days, following much the same pattern as the basal testosterone level. Both testosterone responses and the LH responses were lowest at the end of long days or the beginning of short days.

The stags (except for one stag which failed to cast and hence regrow antlers during one period) grew 4 sets of antlers in response to the manipulated photoperiod (Fig. 1c). Antler casting was associated with very low $\mathrm{LH}$ and testosterone responses at the end of the period of long days, 46-59 days after the change in daylength from short days. Antler cleaning was associated with high concentrations of testosterone during short days, about 55 days after the change in daylength (Table 1).

Table 1. Length of period between the change from long to short days and velvet antler cleaning, and that between the change from short to long days and hard antler casting

\begin{tabular}{ccc}
\hline $\begin{array}{c}\text { Antler growth } \\
\text { period (cycle) }\end{array}$ & $\begin{array}{c}\text { Period from long to short-day } \\
\text { change and antler cleaning } \\
\text { (days) }\end{array}$ & $\begin{array}{c}\text { Period from short to long-day } \\
\text { change and antler casting } \\
\text { (days) }\end{array}$ \\
\hline 1 & $55 \pm 1 \cdot 9(6)$ & $48 \pm 9 \cdot 4(6)$ \\
2 & $56 \pm 3 \cdot 5(6)$ & $53 \pm 5 \cdot 1(5)$ \\
3 & $53 \pm 5 \cdot 3(5)$ & $59 \pm 7 \cdot 8(6)$ \\
4 & $56 \pm 3 \cdot 7(6)$ & $46 \pm 4 \cdot 1(6)$ \\
\hline
\end{tabular}

Values are mean \pm s.d. for the no. of observations in parentheses.

If the individual LH responses, as distinct from the mean of the group, are considered then it is apparent that there may have been another underlying trend, particularly evident in one animal (Stag 8). The LH and testosterone responses for this stag are shown in Fig. 2, together with a diagrammatic portrayal of antler development. Although the major increase in $\mathrm{LH}$ response occurred after the start of short days, there was a significant transitory rise in LH response in 3 of the 4 cycles 1 week after the change from short to long days. In Stag 8 this transitory rise in $\mathrm{LH}$ also induced an increase in testosterone response during long days during cycle 3 but not during the other cycles.

\section{Discussion}

The stags had responded by the 4-week stage of exposure to short days as indicated by the increase in the pituitary $\mathrm{LH}$ response to $\mathrm{GnRH}$. The increase in $\mathrm{LH}$ response to the constant GnRH dose must have been due to an increased pituitary sensitivity to $\mathrm{GnRH}$ or an increased secretory capacity of the pituitary. Melatonin, which is elevated during the night in red deer stags (J. R. Webster \& J. M. Suttie, unpublished) as in sheep (Rollag \& Niswender, 1976), is known to stimulate the onset of gonadal activity via GnRH secretion and hence LH in stags (Lincoln et al., 1984). It therefore seems likely that short days, by increasing the duration of melatonin secretion, increase the secretion of GnRH and hence $\mathrm{LH}$, although the possibility that this increased responsiveness to $\mathrm{GnRH}$ is simply a refractoriness to the previous long day stimulation cannot be excluded. However, this increased responsiveness of $\mathrm{LH}$ to $\mathrm{GnRH}$ during short days was detected in the present study, probably due to the fact that the pituitary is more active at this time in 


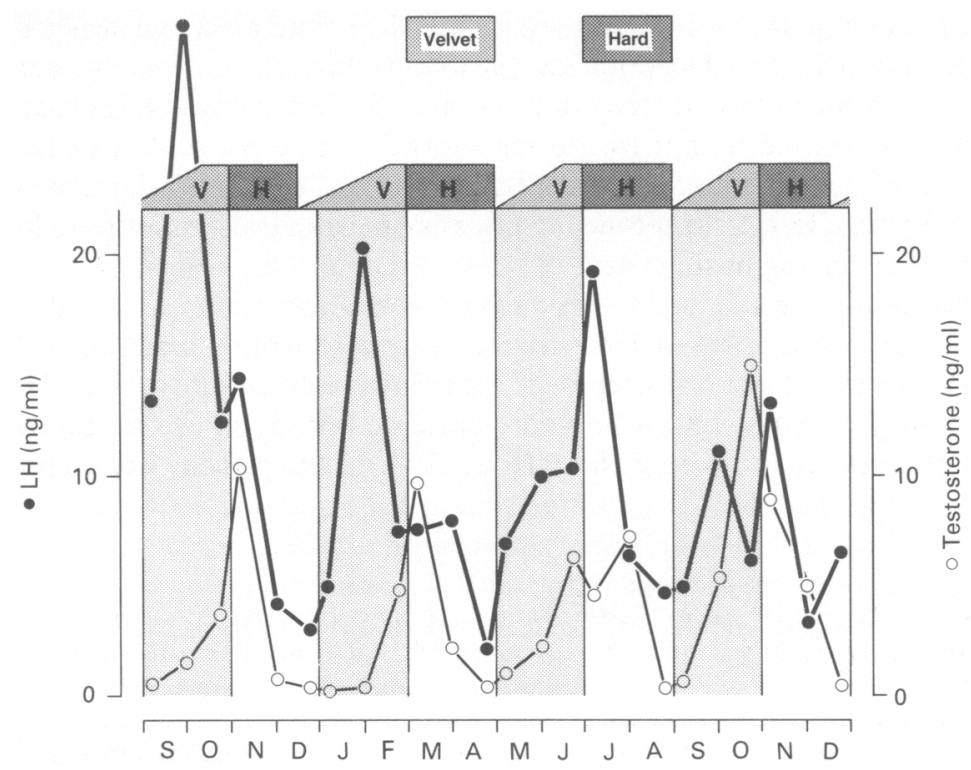

Fig. 2. Individual LH and testosterone responses for Stag 8 during the study. Antler status is shown diagrammatically, with $\mathrm{V}$ indicating velvet antler and $\mathrm{H}$, cleaned hard antler.

response to more frequent GnRH stimulation (Suttie et al., 1984b). The maximal LH responses appeared to decline as the study progressed. This may reflect real changes in the pituitary responsiveness but may also have been due to a relative decline in the dose of GnRH being used as the stags gained bodyweight through the study.

There was some evidence that the responsiveness of LH to GnRH had begun to fall before the end of periods of short days (cycles 1 and 2). This may have been due to refractoriness to stimulation, increasing negative feedback from LH-induced testosterone secretion, or a combination of both. Certainly with the basal samples (Fig. la), it is apparent that high testosterone concentrations in late short days or early long days are associated with low basal LH values. Peak testosterone responses were evident at samplings 1 week before and 1 week after the change to long days. Although long days are not normally stimulatory for testosterone secretion, it is likely that there was a 'carry over' effect. That is, the increased LH during the short days induced a period of gonadal development, which, once started, persisted even in a normally inhibitory long-day environment.

Goss (1969), who found that stags could grow up to 4 sets of antlers in one calendar year, kept his stags on sinusoidally varying photoperiods. The present study demonstrates that alternate short and long (square wave) photoperiods can be used to induce growth of at least 3 sets of antlers annually. Antler casting was associated with low testosterone secretion. Since castration (surgical or chemical: Fennessy \& Suttie, 1985) reduces testosterone and causes antler casting, it is concluded that the 3 sets of antlers cast annually by each stag during the present study were most probably caused by the very low plasma concentrations of testosterone which occurred 3 times during each calendar year. However, since high concentrations of testosterone cause premature antler cleaning (Lincoln et al., 1970), it is considered that the elevated testosterone (as revealed by the elevated testosterone response found in the present study) caused antler cleaning. It is concluded that the changes in testosterone secretion brought about by changes in daylength were responsible for the increased frequency of antler growth cycles in the present study.

The apparently anomalous increase in $\mathrm{LH}$ response to $\mathrm{GnRH}$ during long days which was particularly evident in Stag 8 requires further discussion. It is suggested that, in some stags, any 
change in daylength stimulates $\mathrm{GnRH}$ and hence $\mathrm{LH}$ secretion, although secretion of $\mathrm{LH}$ is not maintained if the daylength is non-stimulatory, i.e. long days. This interesting observation would merit a much more carefully defined study to investigate the possibility of such changes in pituitary response. However, in this respect, there are also a number of reports of two antler cycles during one calendar year on natural daylength (Gillet, 1904; Bedford, 1951; Petzsch, 1959; McEwan, 1968; Suttie \& Kay, 1985), suggesting that the stag must have experienced two reproductive cycles. In addition, Goss (1976) found that sika deer (C. nippon) kept on an artificial photoperiod in which daylength decreased or increased by $2 \mathrm{~h}$ every 4 months cast and regrew their antlers each time the photoperiod changed, irrespective of the direction of change. If it is assumed that a full cycle of antler development is an indicator of a cycle of reproductive development, then it is clear that the deer in Goss's (1969) study responded to each directional change in daylength, with full gonadal development presumably stimulated by GnRH and LH. In the present study no full extra antler cycles were shown, but there was a suggestion that at least one stag responded to each change in daylength with an increase in LH responsiveness. This provides some support for a theory that deer respond to a change in daylength by secreting $\mathrm{GnRH}$ and $\mathrm{LH}$, in a way subtly different from that found in studies with sheep (Lincoln, 1977). In some rare cases referred to above this results in full gonadal and antler development.

\section{References}

Barrell, G.K. \& Lapwood, K.R. (1978/79) Seasonality of semen production and plasma luteinising hormone, testosterone and prolactin levels in Romney, Merino and Polled Dorset rams. Anim. Reprod. Sci. 1, 213-228.

Bedford, Duke of (1951) Pere David's deer: the history of the Woburn herd. Proc. zool. Soc. Lond. 121, 327-333.

Fennessy, P.F. \& Suttie, J.M. (1985) Antler growth: nutritional and endocrine factors. In Biology of Deer Production, pp. 239-250. Eds P. F. Fennessy \& K. R. Drew. The Royal Society of New Zealand Bulletin, Wellington.

Fennessy, P.F., Suttie, J.M., Crosbie, S.F., Corson, I.D., Elgar, H.J. \& Lapwood, K.R. (1988) Plasma LH and testosterone responses to gonadotrophin-releasing hormone in adult red deer (Cervus elaphus) stags during the annual antler cycle. J. Endocr. 117, 35 41.

Goss, R.J. (1969) Photoperiodic control of antler cycles in deer 1 . Phase shift and frequency changes. J. exp. Zool. 170, 311-324.

Goss, R.J. (1976) Photoperiodic control of antler cycles in deer. III. Decreasing versus increasing day lengths. J. exp. Zool. 197, 307-312.

Gillet, F. (1904) Exhibited antlers of Altai stag from London Zoo. Proc. zool. Soc. Lond. 1904, 179.

Lincoln, G.A. (1971) The seasonal reproductive changes in the adult red deer stag (Cervus elaphus L.). J. Zool., Lond. 163, 105-123.

Lincoln, G.A. (1977) Changes in pituitary responsiveness to luteinising hormone releasing hormone in rams exposed to artificial photoperiods. J. Endocr. 73, 519-527.

Lincoln, G.A. \& Kay, R.N.B. (1979) Effect of season on the secretion of $\mathrm{LH}$ and testosterone in intact and castrated red deer stags (Cervus elaphus). J. Reprod. Fert. 55, 75-80.
Lincoln, G.A., Fraser, H.M. \& Fletcher, T.J. (1984) Induction of early rutting in male red deer (Cervus elaphus) by melatonin and its dependence on LHRH. J. Reprod. Fert. 72, 339-343.

Lincoln, G.A., Youngson, R.W. \& Short, R.V. (1970) The social and sexual behaviour of the red deer stag. $J$. Reprod. Fert., Suppl. 11, 71-103.

McEwan, E.H. (1968) Growth and development of the barren ground caribou. II. Postnatal growth rates. Can. J. Zool. 46, 1023-1029.

Niswender, G.D., Reichert, L.E. \& Midgley, A.R. (1969) Radioimmunoassay for bovine and ovine luteinizing hormone. Endocrinology 84, 1166-1173.

Petzsch, H. (1959) Zwei Geweihe bei einem Isubrahirschinnerhalb eines Jahres (Cervus xanthopygus Milne Edwards). Zool. Gart. 24, 517-518.

Rollag, M.D. \& Niswender, G.D. (1976) Radioimmunoassay of serum concentrations of melatonin in sheep exposed to different light regimens. Endocrinology 98 , $482-489$.

Simpson, A.M., Suttie, J.M. \& Kay, R.N.B. (1983/84) The influence of artificial photoperiod on the growth, appetite and reproductive status of male red deer and sheep. Anim. Reprod. Sci. 6, 291-299.

Simpson, A.M., Suttie, J.M., Sharman, G.A.M. \& Corrigall, W. (1983) Influence of some sedative drugs on the appetite of red deer. Vet. Rec. 112, 385.

Smith, O.W. \& Hafs, H.D. (1973) Competitive protein binding and radioimmunoassay for testosterone in bulls and rabbits: Blood serum testosterone after injection of $\mathrm{LH}$ or prolactin in rabbits. Proc. Soc. exp. Biol. Med. 142, 804-810.

Suttie, J.M. \& Kay, R.N.B. (1985) Influence of plane of winter nutrition on plasma concentrations of prolactin and testosterone and their association with voluntary food intake in red deer stags (Cervus elaphus). Anim. Reprod. Sci. 8, 247-258. 
Suttie, J.M., Corson, I.D. \& Fennessy, P.F. (1984a) Voluntary intake, testis development and antler growth patterns of male red deer under a manipulated photoperiod. Proc. N.Z. Soc. Anim. Prod. 44, 167-170.

Suttie, J.M., Lincoln, G.A. \& Kay, R.N.B. (1984b) The endocrine control of antler growth in red deer stags. J. Reprod. Fert. 71, 7-15.
Wilson, P.R. \& Lapwood, K.R. (1979) Studies of reproductive development in Romney rams 1. Basal levels and plasma profiles of $\mathrm{LH}$, testosterone and prolactin. Biol. Reprod. 20, 965-970.

Received 25 May 1988 